\title{
NOTAS PRELIMINARES SOBRE A PANDEMIA E OS SISTEMAS DE PROTEÇÃO SOCIAL NO CONTEXTO DE DOMINÂNCIA FINANCEIRA
}

\section{Preliminary notes on the pandemic and the social protection systems in the context of financial dominance}

Luis Eugenio Portela Fernandes de Souza Instituto de Saúde Coletiva (UFBA). ORCID: https://orcid.org/oooo-0002-3273-8873

Informações do artigo

Recebido em 02/04/2021

Aceito em 08/04/2021

doi>: https://doi.org/10.25247/2447-861X.2021.n252.pg-17

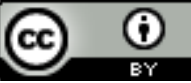

Esta obra está licenciada com uma Licença Creative Commons Atribuição 4.0 Internacional.

\section{Como ser citado (modelo ABNT)}

SOUZA, Luis Eugenio Portela Fernandes de. Notas preliminares sobre a pandemia e os sistemas de proteção social no contexto de dominância financeira. Cadernos do CEAS: Revista Crítica de Humanidades.

Salvador/Recife, v. 46, n. 252, p. 9-17, jan./abr. 2021. DOI: https://doi.org/10.25247/2447-861X.2021.n252.pg-17

\begin{abstract}
Resumo
Sob dominância financeira, o capitalismo tem se apoiado em políticas neoliberais que fragilizam os sistemas de proteção social. No contexto da covid-19, ainda que cumprindo um papel fundamental na mitigação dos efeitos da pandemia, os sistemas de proteção social não têm sido capazes de evitar o aprofundamento da crise social e sanitária instalada. Essa incapacidade sugere que o maior obstáculo ao controle da pandemia e à superação da crise social não está no tipo de vírus ou nas características clínicas e epidemiológicas da covid-19, mas sim na dinâmica do modo produção vigente e as opções de políticas públicas decorrentes. Com efeito, ao tempo em que a lógica financeira domina a dinâmica econômica, fortalecem-se correntes políticas antidemocráticas que, no comando de governos, ameaçam aniquilar os sistemas de proteção social. Diante do risco da barbárie, contudo, forças democráticas e socialistas têm a oportunidade de acender uma luz de esperança neste turbulento início de século.
\end{abstract}

Palavras-Chave: Sistemas de proteção social. Dominância financeira. Pandemia.

Abstract

Under financial dominance, capitalism has made use of neoliberal policies that have weakened social protection systems. In the context of covid-19, although playing a fundamental role in mitigating the effects of the pandemic, social protection systems have not been able to prevent the deepening of the social crisis that accompanies it. This inability suggests that the biggest obstacle to controlling the pandemic and overcoming the social crisis is not the type of virus or the clinical and epidemiological characteristics of the disease, but the dynamics of the current mode of production and the resulting public policy options. Indeed, at the same time that the financial logic dominates the economic dynamics, antidemocratic political currents are being strengthened, which, at the command of governments, threaten to annihilate social protection systems. Faced with the risk of barbarism, however, democratic and socialist forces have the opportunity to shine a light of hope in this turbulent beginning of the century.

Keywords: Social protection systems. Financial dominance. Pandemic. 
A pandemia de covid-19 tem chamado a atenção para os sistemas de proteção social - proteção ao trabalho, assistência social e saúde, principalmente. Por um lado, reconhecese sua importância para a mitigação dos efeitos da pandemia, e, por outro, constata-se a insuficiência crônica de investimentos e sua incapacidade de impedir o aprofundamento das desigualdades sociais.

O presente texto tenciona discutir, em notas preliminares, a situação atual e as perspectivas dos sistemas de proteção social no estágio de dominância financeira do capitalismo. Para tanto, começa caracterizando, de maneira breve, a financeirização da economia. A seguir, apresenta uma revisão sucinta do desempenho dos sistemas de proteção social diante da pandemia no mundo e no Brasil. E, finalmente, discute como a orientação neoliberal das políticas públicas, consentânea à dominância financeira, não apenas fragiliza os sistemas de proteção social, como favorece a emergência de práticas antidemocráticas que podem levar à aniquilação de qualquer ideia de Estado de bem-estar social.

A financeirização econômica nomeia o fato de a riqueza financeira ou "de papel" passar a se multiplicar de modo relativamente independente da produção e da circulação dos bens e serviços com valor de uso. Ao se expandir por toda a economia, a financeirização se torna dominante, significando que empresas dos mais diferentes ramos passam a auferir parte significativa de seus lucros das atividades financeiras, vindo, frequentemente, a se transformar em conglomerados multissetores, sob o comando centralizado de suas tesourarias. É essa dinâmica que caracteriza o estágio atual do capitalismo como de dominância financeira (BRAGA, 2009).

Dados os grandes volumes de recursos que movimentam, os fundos públicos são alvos preferenciais dos capitalistas-rentistas. A rigor, a financeirização não existiria sem o acesso aos fundos públicos (KARWOWSKI; CENTURION-VICENCIO, 2018). Não é por outra razão que todo o sistema de proteção social, incluindo os sistemas públicos de previdência social e de saúde, está sob ataque do capital, inclusive no Brasil (SILVA, 2018).

Vale lembrar que, à financeirização, no plano da economia, corresponde o neoliberalismo, no plano da política. O neoliberalismo vem apresentando, há quatro décadas, as justificativas ideológicas e as orientações para as iniciativas de ataque às políticas sociais.

Extensa revisão de estudos sobre a implantação de programas de proteção social durante pandemias prévias e, principalmente, durante a atual pandemia de covid-19 (ABDOUL-AZIZE; GAMIL, 2020) evidencia que, embora sejam instrumentos relevantes de 
resposta às crises sanitárias, os programas sociais carecem de estratégias abrangentes, limitando-se a medidas pontuais, destinadas aos grupos mais afetados pelas pandemias.

Um quadro mais sombrio é pintado por pesquisa da Oxfam e Development Pathways (BARBA et al., 2020), ao informar que mais de 2,7 bilhões de pessoas não receberam nenhum apoio financeiro dos governos durante a pandemia. A pesquisa mostra também que, quando existente, o auxílio para desempregados, idosos ou crianças, em países de baixa e média renda, tem sido suficiente para atender às necessidades básicas.

Razavi et al. (2020), por sua vez, afirmam que a pandemia de covid-19 deu impulso a uma abordagem mais inclusiva de proteção social, reduzindo lacunas de cobertura, especialmente para trabalhadores informais. Acrescentam, no entanto, que as medidas de proteção implementadas foram temporárias, de poucos meses, em geral. Por fim, salientam que a fragilidade dos sistemas de proteção social, evidenciada pela pandemia de covid-19, põe em risco a própria coesão social.

Também no Brasil tem sido importante o papel dos sistemas de proteção social no enfrentamento da pandemia. Com efeito, o Sistema Único de Saúde (SUS) foi capaz de expandir rapidamente o número de leitos hospitalares para assistir aos doentes de covid-19, tendo recebido, em 2020, cerca de $30 \%$ a mais de recursos federais do que o orçado previamente. Em 2021, entretanto, o orçamento do Ministério da Saúde voltou ao nível prépandêmico (MORETTI et al., 2020). Na assistência social, foram adotadas medidas de retenção do emprego e alívio tributário a empresas, incluindo a redução proporcional de jornada de trabalho e de salários e a suspensão temporária do contrato de trabalho durante o estado de calamidade pública. Adotou-se também o auxílio financeiro emergencial pago a desempregados, microempreendedores individuais e trabalhadores informais por oito meses em 2020 e, posteriormente, com valores inferiores e critérios de elegibilidade mais restritos por quatro meses em 2021. Em todos os casos, como demonstram Tavares et al. (2020), as medidas foram adotadas tardiamente e em nível insuficiente.

Assim, mesmo tendo sua importância reconhecida na mitigação dos efeitos, os sistemas de proteção social, em geral, não têm sido fortalecidos a ponto de serem capazes de controlar a pandemia e evitar o agravamento da crise social que a acompanha. De fato, à exceção de alguns países da região Ásia-Pacífico (China, Vietnam, Taiwan, Singapura Austrália e Nova Zelândia), o que se vê é a sucessão de ondas epidêmicas da covid-19 e o aprofundamento das desigualdades sociais (SHADMI et al., 2020). 
Percebe-se, então, que a dificuldade de superar a crise sociossanitária não se deve às características do vírus ou da doença, mas sim à fragilidade dos sistemas de proteção social. Ora, a dominância financeira e o neoliberalismo têm sido algozes dos sistemas de proteção social (LAVINAS, 2018; SESTELO et al. 2020), os quais poderiam não apenas mitigar os efeitos da pandemia, mas, antes, impedir que zoonoses se transformassem em catalisadores de grandes crises sociais.

Mesmo onde ainda resistem, nos países centrais do capitalismo particularmente, os sistemas de proteção social se encontram distantes da pujança que tiveram nos trinta anos que se seguiram ao fim da $2^{\text {a }}$ Grande Guerra (KERSTENETZKY; GUEDES, 2018). Em consequência, inclusive nos países mais ricos, as desigualdades se acentuam. A título de exemplo, basta registrar que a expectativa de vida ao nascer parou de crescer - e tem se reduzido, dentre os mais pobres - desde 2010 no Reino Unido (MARMOT et al., 2020). Os sistemas de proteção perderam a capacidade de mitigar a geração de iniquidades pelo modo de produção social em seu estágio atual.

No Brasil, desde antes da pandemia, mudanças legais, claramente influenciadas pelos interesses do mercado financeiro, vêm enfraquecendo o sistema da proteção social nas áreas de trabalho, previdência pública, assistencial social e saúde. Já no período da pandemia, assiste-se ao aguçamento da insegurança social, com aumento da perda de renda e redução do acesso a bens e serviços (CASTRO, 2020), caracterizando um verdadeiro estado de malestar social.

Vive-se, portanto, uma crise de múltiplas dimensões, cujos elementos estruturais estão ligados ao estágio atual do modo de produção capitalista. Em consequência, pode-se admitir que o maior obstáculo à superação da crise reside, em última instância, no sistema de poder que sustenta esse modo de produção.

O que é, talvez, mais alarmante é a falta de perspectiva de superação dessa crise estrutural, no sentido do fortalecimento dos sistemas de proteção social, da redução das desigualdades e do enfrentamento da crise climática. De fato, o que se constata é a reafirmação das opções políticas que trouxeram o mundo a esta crise, a começar pela continuação de grandes investimentos na indústria de combustíveis fósseis durante a pandemia (QUITZOW et al. 2021), mesmo se sabendo da relação entre degradação ambiental e emergência de zoonoses como a covid-19 (VENTURA, GIULIO, RACHED, 2020). 
A reafirmação dessas opções pode ser explicada pelo poderio do capitalismo financeirizado, bem representado pelos 2.153 bilionários que têm mais riqueza do que 4,6 bilhões de pessoas ou cerca de 60\% da população mundial (OXFAM, 2020). Essa elite social não vacila em apoiar ou mesmo em recorrer, se necessário, à preservação de seus interesses, a movimentos de extrema-direita que se apresentam como a alternativa ao statu quo, mobilizando os "perdedores" da globalização econômica, os ressentidos da perda de status social e também grupos sociais sensíveis aos valores da moral conservadora, de base cristã, branca e patriarcal.

Wendy Brown (2019), no seu livro "Nas ruínas do neoliberalismo", discute as razões da ascensão da política antidemocrática no Ocidente. Argumenta, convincentemente, que a ameaça à democracia, que pode levar ao aniquilamento dos sistemas de proteção social, em vários países do mundo, tem suas raízes nas políticas neoliberais.

A autora lembra, inicialmente, o ataque do neoliberalismo à própria ideia de social ou de sociedade. Para Hayek, referir-se ao social ou à sociedade não passa de um eufemismo para o poder coercitivo do governo. Radicalizando essa concepção, Margareth Thatcher (1987) dizia que só existem indivíduos, não existe "such a thing as society".

Brown destaca, em segundo lugar, o ataque do neoliberalismo às formas democráticas de tomada de decisão política. Em lugar de deliberação, contestação e partilha democráticas de poder, que eventualmente representam obstáculos ao livre funcionamento do mercado, o neoliberalismo propõe a gestão e a tecnocracia, facilitadoras da proeminência do capital. E é assim que funciona: por exemplo, o Parlamente europeu e os Estados nacionais europeus, na prática, delegaram à troika, formada pela Comissão Europeia, pelo Banco Central Europeu e pelo Fundo Monetário Internacional, o poder de ditar a política econômica do continente (GEORGIEVA, 2011).

De modo perspicaz, a autora acrescenta que o projeto neoliberal não se resume a promover a primazia do mercado, mas tem como seu segundo elemento fundamental a expansão do alcance da moralidade tradicional para além das esferas familiar e privada até a vida pública e econômica.

E cita, textualmente, Hayek, em discurso de 1984: "Devemos retornar a um mundo em que não apenas a razão, mas a razão e a moral, como parceiras iguais, devem governar nossas vidas, onde a verdade da moral é simplesmente uma tradição moral, a do Ocidente cristão, que criou a moral na civilização moderna" (BROWN, 2019, p.109). Essa tradição moral 
define, claramente, o lugar da mulher, do não-branco, do pobre, do diferente na sociedade, tirando qualquer sentido a políticas universais e igualitárias de proteção social.

Finalmente, Wendy Brown mostra como o projeto mercado-e-moral, na prática, se concretiza na mercantilização da moral. A liberdade passa a ser uma 'calça velha, azul e desbotada', na propaganda de uma marca de blue jeans, e o sonho de Martin Luther King passa a ser dirigir uma caminhonete potente, na propaganda de um fabricante de automóveis. Não há, portanto, valores outros além do êxito material, não há ética fora dos interesses econômicos. Crescem, assim, o niilismo e o vale-tudo. Em consequência, rompese qualquer laço de empatia, qualquer sentido de solidariedade, ou seja, perde-se a base ética de sustentação de qualquer sistema de proteção social.

Esse contexto, provavelmente, explica porque a situação atual dos sistemas de proteção social é de fragilidade, com os mesmos estando incapazes de controlar a pandemia e superar a crise social presente. Mostra, também, que não são alentadoras as perspectivas, haja vista o risco de políticas antidemocráticas conduzirem à aniquilação desses sistemas fragilizados. Tendência, contudo, não é destino, como disse René Dubos e como mostra a experiência histórica.

Em meados do século $X X$, no período de ascensão do nazi-fascismo, Karl Polanyi publicou "A Grande Transformação", onde argumenta que, quando o mercado deixa de ser um espaço limitado de trocas econômicas e, por meio da ação do Estado, separa-se das demais instituições sociais, tendo transformado o trabalho, a terra e o dinheiro em mercadorias, nesse momento, a sociedade corre o risco da aniquilação. Diz Polanyi, "a total frustração da liberdade no fascismo é, com efeito, o resultado inevitável da filosofia liberal" (POLANYI, 2000, p. 298).

Após destruição produzida pela $2^{a}$ Grande Guerra, a humanidade foi capaz de se erguer e se renovar. As nações democráticas conseguiram reorientar a ação estatal no sentido de regular, controlar, dar limites ao mercado. Nesse processo, os sistemas de proteção social, seja nas experiências da socialdemocracia, seja nas do socialismo real, foram pilares centrais desse soerguimento e dessa renovação.

No início do século XXI, como consequência de 40 anos de dominância financeira neoliberal, vivemos um novo risco de aniquilação da sociedade com a ascensão da política antidemocrática. Na verdade, vivemos a ameaça da aniquilação não apenas da sociedade humana, mas de toda a vida no planeta. 
Estamos caminhando para o fim? Talvez, sim. Talvez, não.

No auge de seu poder, os nazistas anunciaram um império de mil anos. Seis anos após terem iniciado a guerra com a invasão da Polônia, estavam derrotados. Assim como as forças democráticas e socialistas venceram o fascismo em 1945 e implantaram sistemas de proteção que promoveram o desenvolvimento social, as forças democráticas e socialistas deste início de século XXI saberão articular, em um só projeto de sociedade, a promoção do bem comum e o respeito às diferenças e, assim, poderão mobilizar a esperança de milhões, vencer o neofascismo filho do neoliberalismo e implantar sistemas de proteção social que contribuam para a construção de sociedades mais justas.

\section{REFERÊNCIAS}

ABDOUL-AZIZI, Hamidou Taffa; EL-GAMIL, Rehab. Social Protection as a Key Tool in Crisis Management: Learnt Lessons from the COVID-19 Pandemic. Global Social Welfare (2021) 8:107-116. https://doi.org/10.1007/s406o9-020-00190-4

BARBA, Liliana Marcos; VAN REGENMORTEL, Hilde; EHMKE, Ellen. Refugio en la tormenta: necesidades globales de protección social universal en tiempos del COVID-19. Disponível em: https://www.oxfam.org/es/informes/refugio-en-la-tormenta-necesidadesglobales-de-proteccion-social-universal-en-tiempos-del. Acesso em 13/06/2021.

BRAGA, José Carlos. Crise sistêmica da financeirização e a incerteza das mudanças. Estudos Avançados, 23(65), 89-102, 2009. https://doi.org/10.1590/So10340142009000100006

BROWN, Wendy. Nas ruínas do neoliberalismo: a ascensão da política antidemocrática no Ocidente. São Paulo: Editora Politeia, 2019

CASTRO, Jorge Abrahão. Proteção social em tempos de Covid-19. SciELO Preprints, 2020. Disponível em: https://preprints.scielo.org/index.php/scielo/preprint/view/1186/version/1271 Acessado em 12 de junho de 2021.

GEORGIEVA, Emilia. The role of EU institutions in implementing its monetary policy. Eastern Journal of European Studies, Volume 2, Issue 1, June 2011.

KARWOWSKI, Ewa; CENTURION-VICENCIO, Marcos. Financialising the state: recent developments in fiscal and monetary policy. Working Papers halshs-01713028, HAL, 2018.

KERSTENETZKY, Celia Lessa ; GUEDES, Graciele Pereira. O Welfare State resiste? Desenvolvimentos recentes do estado social nos países da OCDE. Ciência e Saúde Coletiva, vol.23, n.7, 2018. https://doi.org/10.1590/1413-81232018237.08702018.

LAVINAS, Lena. The Collateralization of Social Policy under Financialized Capitalism. Development and Change, 49: 502-517, 2018. https://doi.org/10.1111/dech.12370 
MARMOT, Michael; ALLEN, Jessica; BOYCE, Tammy; GOLDBLATT, Peter; MORRISON, Joana. Health equity in England: The Marmot Review 10 years on. London: Institute of Health Equity, 2020. http://www.instituteofhealthequity.org/resources-reports/marmotreview-10-years-on/the-marmot-review-10-years-on-full-report.pdf

MORETTI, Bruno; OCKÉ, Carlos; FUNCIA, Francisco. Por que o SUS não pode perder R\$35 bi em 2021, em meio à pandemia? Disponível em: https://cee.fiocruz.br/?q=node/1242. Publicado em 27/08/2020. Acesso em 13/06/2021.

OXFAM. Bilionários do mundo têm mais riqueza do que $60 \%$ da população mundial. Disponivel em: https://www.oxfam.org.br/noticias/bilionarios-do-mundo-tem-maisriqueza-do-que-6o-da-populacao-mundial. Publicado em 19/01/2020. Acesso em $02 / 04 / 2021$.

POLANYI, Karl. A grande transformação: as origens de nossa época. 2. ed. Tradução de Fanny Wrabel. Rio de Janeiro: Compus, 2000.

QUITZOW, Rainer; BERSALLI, German; EICKE, Laima; JAHN, Joschka; LILLIESTAM, Johan; LIRA, Flavio; MARIAN, Adela; SÜSSER, Diana; THAPAR, Sapan; WEKO, Silvia; WILLIAMS, Stephen; XUE, B. The COVID-19 crisis deepens the gulf between leaders and laggards in the global energy transition. Energy Research and Social Science, 74, 2021, 101981. https://doi.org/10.1016/j.erss.2021.101981

RAZAVI, Shahra; BEHRENDT, Christina; BIERBAUM, Mira; ORTON, Ian; TESSIER, Lou. Reinvigorating the social contract and strengthening social cohesion: Social protection responses to COVID-19. International Social Security Review, Vol. 73, 3/2020. https://doi.org/10.1111/issr.12245

SESTELO, José Antônio de F.; CARDOSO, Artur M.; BRAGA, lalê F.; MATTOS, Leonardo V.; ANDRIETTA, Lucas $S$. Financeirização das políticas sociais e da saúde no Brasil do século XXI: elementos para uma aproximação inicial. Economia e Sociedade, 26, 1097-1126, abril 2018.

SHADMI, Efrat; CHEN, Yingyao; DOURADO, Inês; FARAN-PERACH, Inbal; FURLER, John; HANGOMA, Peter; HANVORAVONGCHAI, Piya; OBANDO, Claudia; PETROSYAN, Varduhi; RAO, Krishna D.; RUANO, Ana Lorena; SHI, Leiyu; DE SOUZA, Luis Eugenio; SPITZERSHOHAT, Sivan; STURGISS, Elizabeth; SUPHANCHAIMAT, Rapeepong; URIBE, Manuela Villar; WILLEMS, Sara. Health equity and COVID-19: global perspectives. International Journal for Equity in Health, v. 19, p. 104, 2020.

SILVA, Maria Lúcia L. Contrarreforma da Previdência Social sob o comando do capital financeiro. Serviço Social \& Sociedade, v. 131, p. 130-154-154, 2018.

TAVARES, Amarílis Busch; SILVEIRA, Fabrício; PAES-SOUSA, Rômulo. Proteção Social e COVID-19: a resposta do Brasil e das maiores economias da América Latina. Revista NAU Social, v.11, n.20, p. $111-129$ maio / out 2020 
THATCHER, Margareth. Interview for Woman's Own ("no such thing as society") 1987 Sep 23. Margareth Thatcher Foundation.

https://www.margaretthatcher.org/document/106689. Acesso em 02/04/2021.

VENTURA, Deisy de Freitas Lima; DI GIULIO, Gabriela Marques; RACHED, Danielle Hanna. Lessons from the Covid-19 pandemic: sustainability is an indispensable condition of Global Health Security. Ambiente \& Sociedade, São Paulo. Vol. 23, 2020.

http://dx.doi.org/10.1590/1809-4422asoc20200108vu2020L3ID.

\section{Detalhes do autor}

Luis Eugenio Portela Fernandes de Souza

Doutor em Saúde Pública (U. de Montreal, 2001). Professor assoc. do Instituto de Saúde Coletiva (UFBA). Email: luiseugenio@ufba.br. ORCID iD: https://orcid.org/0000-0002-3273-8873. 